\title{
FLORISMUNDO PERIQUITO: A DESCOBERTA DE UM CONTO GOIANO
}

\author{
Ionice Barbosa de Campos \\ Mestra em Letras pela Universidade Federal de Uberlândia (UFU) \\ ionice.barbosa@gmail.com
}

\section{RESUMO}

Faremos aqui uma breve análise do conto que dá título ao livro de José Godoy Garcia, "Florismundo Periquito", a fim de mostrar o que a prosa godoyana tem para nos oferecer no que concerne à reflexão sobre o processo migratório que se encontra na literatura produzida em Goiás e mostrar como esse espaço expulsa e, ao mesmo tempo, acolhe seus transeuntes. Os personagens dessa narrativa, sempre instalados nas margens sociais, chamam nossa atenção para a discussão de uma teoria pautada em filósofos como Foucault e Deleuze, que tematizam esse assunto em suas obras, além, é claro, de enviesar a discussão para a representação de uma estética que nos permite verificar como os deslocamentos humanos estão presentes e influentes nas vidas dos personagens, com maior ou menor intensidade, mas nunca deixando o espaço em branco, uma vez que está sempre preenchido por uma identidade pessoal e/ou social.

Palavras-chave: literatura social, migração interna, personagens das bordas, José Godoy Garcia.

\begin{abstract}
Our intent is to do a brief analysis of José Godoy Garcia's short story "Florismundo Periquito" in order to demonstrate how Godoyan prose can offer us thoughts about the migratory process found in the literature produced in Goiás. Also, we wish to show how this space expels and, at the same time, welcomes its bystanders. The characters of the narrative, always installed in the social margins, call our attention to Foucault and Deleuze's theories and skew the discussion about the representation of an aesthetics to allow us to verify how human displacements are present and influential in the lives of the characters, to a greater or lesser extent, but never leaving the space empty as it is always filled by a personal and/or social identity.
\end{abstract}

Keywords: social literature, characters of the fringes, José Godoy Garcia. 


\section{Introdução}

O livro de contos de José Godoy Garcia, intitulado Florismundo Periquito, cumpre a função de consolidar a carreira do autor como prosador. Uma obra peculiar, com várias narrativas representando os sertões de Goiás e evidenciando histórias de famílias destinadas à descentralização, ou seja, todos os personagens estão nas bordas, margeados socialmente. Além disso, o espaço onde se encontram os personagens, de um modo geral, é um lugar ermo, em que as condições de vida são precárias e, por esse motivo, as pessoas vivem em trânsito, procurando a mínima sobrevivência. Em toda a prosa de Godoy Garcia, encontramos esse tema da migração, em que as narrativas se destinam a contar histórias de uma gente que vive em busca de algo novo, de um espaço acolhedor.

Tal espaço, por sua vez, ao mesmo tempo que expulsa, acolhe, visto que não muda muito, já que é o interior do estado de Goiás, onde as pessoas de uma mesma classe social, a baixa, acabam por unir-se em prol de sua causa em comum: sobreviver. Sendo assim, quando saem de um lugar, ou são expulsos, destinam-se a outro, onde serão acolhidos, no entanto, o processo cíclico é o mesmo, acabam por não ter como sobreviver e, assim, a caminhada continua, até não ter mais para onde ir. É para esse desfecho que o texto literário de Godoy Garcia nos conduz, especificamente no conto aqui em tela. Acompanhamos, enquanto leitores, a trajetória da família de Florismundo Periquito, que busca, dia após dia, um lugar que os acolha.

Aqui, os personagens são todos representantes de uma minoria, a classe operária, com a intensificação de um de seus membros ser deficiente, ao que tudo 
indica, físico e mental, o que leva a classe ideológica a rejeitar, ainda com mais veemência, a família. No entanto, no decorrer da narrativa, percebemos que o deslocamento causa mudanças na trajetória e na identidade de alguns personagens, principalmente em Florismundo, esse ser considerado inútil na sociedade. É a partir dessa ideia que a leitura do conto pode ser realizada com suporte nas obras de Foucault (2003) e Deleuze (2011), entre outros estudiosos, tendo em vista que suas teorias se voltam para a discussão do ontológico e se debruçam sobre questões como filosofia, psicanálise, política e literatura, as quais estão intrinsicamente ligadas ao homem.

Em específico, o conto que dá nome ao livro - "Florismundo Periquito" - será destaque neste artigo, no qual discutiremos, à luz de Deleuze (2011), por exemplo, sobre a singularidade de Fló, o protagonista da história. Por singularidade, entendemos as características que o diferenciam das demais pessoas de sua família e de todo mundo que o cerca, uma vez que Florismundo não tem uma identidade comum e que o define, pelo contrário, ele diferencia-se do igual e, por isso, não está submisso a um único princípio ou fundamento, ele é mais diferente que igual. Sua identidade preenche o espaço social e físico em que vive, porque é um personagem completo, por mais paradoxal que isso possa parecer quando lembramos de seus “defeitos" físicos e psíquicos. Nas palavras de Deleuze (1997, p. 95-96):

Cada original é uma potente Figura solitária que extravasa qualquer forma explicável: lança flamejantes dardos-traços de expressão, que indicam a teimosia de um pensamento sem imagem, de uma questão sem resposta, de uma lógica extrema e sem racionalidade. 
Fló é esse ser original, essa figura solitária que o estudioso afirma possuir um caráter paradoxal, uma vez que, ao mesmo tempo, é simples e complexo, vive em um mundo "real", porém cheio de irracionalidade. Contudo, há que se pensar que essa inexistência de lógica é algo visto por quem está "de fora", pela família e pelo leitor (talvez), porque, para o personagem, tudo está organizado e seu pensamento é racional, tanto que, na narrativa, ele é o único que se mantém vivo e, apesar de estar sempre em silêncio e solitário, consegue enxergar e entender o que acontece ao seu redor.

Em linhas gerais, nos contos de José Godoy Garcia, o autor parece saber quando o leitor é capaz de seguir com ele, no mesmo ritmo da captação da realidade, e escolher um tema para começar a desvendá-lo. Temas estes que, na maioria das vezes, giram em torno da revelação da essência da condição humana e volta-se para discussões dos seres marginalizados e que não têm vez e voz diante da sociedade ideológica, incluindo os que são, por alguma necessidade, obrigados a deixarem suas terras e dirigirem-se a paragens desconhecidas, a fim de conquistarem algo novo.

Essas pequenas narrativas godoyanas merecem atenção por estarem inscritas na ordem dos contos populares. Antonio Carlos Hohlfeldt $(1988$, p. 14) afirma, nas águas de Câmara Cascudo, que um conto revela "informação histórica, etnográfica, sociológica, jurídica, social. É um documento vivo, denunciando costumes, ideias, mentalidades, decisões e julgamentos". Assim, a prosa contista de José Godoy Garcia revela esse caráter documental e social, a partir do posicionamento do autor, para captar a sensibilidade do leitor, definindo, dessa forma, o caráter estético da obra. 
Sendo elaborados de acordo com as características que definem esse gênero, alguns elementos dos contos que encontramos em Florismundo Periquito podem, também, serem vistos na poesia e no romance de José Godoy Garcia. Um exemplo de tal afirmação encontramos no conto que dá título ao livro, pois tem uma relação inter e intratextual com o poema "O menino que não sabia morrer", do seu livro de poemas Os Morcegos, cuja primeira edição é de 1987; o mesmo acontece com outro conto, "Neco e Joza", que é um recorte do romance O Caminho de Trombas.

Perfazendo um caminho rápido sobre os contos do livro, de maneira geral, vimos que são narrativas retratando fatos do cotidiano, em cidades pequenas e interioranas, onde a população vive em decadência social. Ao todo, são onze contos que trazem, no dizer do autor, "historietas simples, ou simplórias", mas que sabemos não ser apenas isso, uma vez que carregam um significado ontológico perceptível a cada página lida. Enfim, percebe-se, após a leitura dos contos, uma mesma linha/vertente que permeia todos eles: a temática, o espaço, as características dos personagens das bordas, a necessidade de migração, na maioria das vezes, do espaço rural para o urbano. Mas, como já dito, vamos aqui nos ater à análise de apenas um texto da obra.

\section{Florismundo em seu mundo}

"Florismundo Periquito" é um conto relativamente grande, se compararmos aos modelos mais tradicionais e exemplificados pelos teóricos que comentamos anteriormente, o que não nos impede de fazer sua leitura e levantar algumas 
discussões sobre o tema que perpassa a narrativa. Fló, como era chamado pelos membros de sua família, fingia-se de morto, ou talvez, nem ele mesmo se dava conta disso, "era um menino que não sabia morrer" (GARCIA, 1990, p. 75). O conto narra a saga de uma família grande, constituída por pai, mãe, dez filhos vivos e seis que já haviam morrido, fala da água e da terra; valorizando sempre o elemento vivo que corre nos rios e fecunda a terra, a água é sempre destaque na narrativa.

Fló vivia em um saco, carregado sempre pelos outros membros da família que, por sua vez, achavam que ele morreria logo e pensavam que assim seria até melhor. Em toda a história, percebemos um questionamento levantado acerca do riso de Fló. Seria seu riso o fio da vida que não o deixava morrer? Ou, talvez, sua constante necessidade de contato com a água? Pelas descrições do personagem no texto, fica evidente que Fló era deficiente físico, limitado em viver sua vida plenamente, mas ele ouvia, falava e pensava. Sua característica peculiar era o riso contagiante. Um de seus irmãos sempre dizia que talvez ele nunca morresse porque estava sempre rindo.

Foucault (2003) pode nos dar respostas para as questões colocadas, tendo em vista que em um capítulo de História da Loucura fala da nau dos loucos e do seu lugar na sociedade. Fló não era, necessariamente, considerado louco, mas, de qualquer forma, um ser marginalizado na sociedade, aquele do qual os demais querem distância, às vezes, os próprios pais. Como lemos: "Zé Periquito adormeceu nele a ideia de que era pior para o filho continuar vivendo. Não dizia, mas a mãe Maria Gomes pensava igual" (GARCIA, 1990, p. 76). Foucault lembra que sujeitos como Fló precisavam ser expurgados da sociedade para que se fundamentasse uma 
"higienização", sendo assim, a sociedade ficaria livre dos loucos, dos mendigos, dos bêbados, dos doentes mentais e físicos e toda classe considerada inferior.

A discussão teórica foucaultiana da obra citada gira em torno do "jogo da exclusão", isto é, do banimento e encarceramento que os marginalizados deveriam ser submetidos até meados do século XIX, mesmo com o nascimento da psiquiatria moderna. Para tanto, a "nau dos loucos" é suscitada para levá-los à segregação. Nas palavras de Foucault (2003, p. 11-12):

[...] confiar o louco aos marinheiros é com certeza evitar que ele ficasse vagando indefinidamente entre os muros da cidade, é ter a certeza de que ele irá para longe, e torná-lo prisioneiro de sua própria partida. Mas a isso a água acrescenta a massa obscura de seus próprios valores: ela leva embora, mas faz mais que isso, ela purifica. Além do mais, a navegação entrega o homem à incerteza da sorte: nela, cada um é confiado a seu próprio destino, todo embarque é, potencialmente, o último. É para o outro mundo que parte o louco em sua barca louca; é do outro mundo que ele chega quando desembarca. Essa navegação do louco é simultaneamente a divisão rigorosa e a Passagem absoluta.

Do lado oposto ao do isolamento, tem-se o que podemos chamar de "válvula de escape" para esses sujeitos das bordas, temos o elemento água que é, de certa forma, libertador, pois leva o indivíduo para outro mundo, livrando-o do que antes lhe prendia e agoniava. É, exatamente, o que ocorre com Fló sempre que se vê banhado nas águas dos rios. O contato com esse elemento fluido lhe abre caminhos, lhe dá vida, e torna-o dono de seu próprio destino, sendo capaz de viver ali eternamente, indo e vindo de mundos diferentes e seus, particulares, próprios, além de se sentir purificado. 
São várias as passagens que fazem menção ao elemento água no conto, a primeira delas, já na página inicial, revela o seguinte:

Essas estradas são assim: as águas fazem o homem forte, as águas costuram a vidinha e das entranhas da terra-mulher brotam esses rebentos tristes que andam por aí. Dizemos as águas, que da terra não sai muita sangria, a terra é vida, mas ela tem dono e os homens nascem e morrem na sua mão (GARCIA, 1990, p. 75).

No trecho, diz que a terra tem dono, prende o homem, mas a água, como vimos em Foucault (2003), é purificadora, redentora. Por isso, Fló sente-se tão bem quando o levam para banhar nas águas correntes, é o lugar onde ele pode sentir/ter, inclusive, contato com um poder sobrenatural/divino de cura interior e exterior de todos os seus males. Ademais, há um elemento místico na ligação com a água, visto que ora a relacionam com Deus, ora com lendas populares, ora com espíritos outros. Vale deixar aqui algumas partes caracterizadoras desse contato:

Fló ficava horas à porta olhando os meninos que passavam na rua. Ele ficava pensando às vezes nas águas dos rios; perdia-se pensando e imaginando as águas que passavam correndo sem fim. Tudo porque um dia um velho chamado Jerusalvo lhe contou que as águas nasciam na Lua e desciam à Terra e corriam levadas pela força da Lua (GARCIA, 1990, p. 80-81).

Joaquim achou que deviam levar Fló às águas do riacho e o pai logo recusou a ideia. Nunca conversavam, mas Joaquim agora teve alento. 
- A água, pai, é um bem de Deus. A água lava o corpo e tira os males. A água é feita só para o bem. Quem sabe a gente dá um banho nele? O Fló vai ter mais fé com a água no corpo.

- Me pego com Deus que não seja um mal, disse o pai.

- Não, não é um mal, a água é um bem de Deus.

$[\ldots]$

Levaram o irmão e o despiram à beira do córrego que corria na mata restinga. Fló, quando o sol já ia alto, andava rindo. DeramIhe mais banho e ele se tornou vigoroso dentro de sua enorme fraqueza. Fló sentia a água. Era como um pássaro sentindo o ar no peito nos vôos altos. A água afinava o sangue. Ele considerava que $o$ ser vivente é bom como a água, ela faz parte do ser vivente. Jerusalvo contava muitas coisas da água. O negro era um irmão da água (GARCIA, 1990, p. 87-88. Grifos nossos).

A água, portanto, parece ser a condutora da vida de Fló. Bachelard (1997), em A água e os sonhos, resgata os significados ligados ao elemento fluido que aqui mencionamos. Especificamente no capítulo "Pureza e purificação. A moral da água", o crítico pondera sobre esse elemento como "símbolo natural para a pureza". A partir dos excertos do texto literário citados acima, podemos fazer uma leitura comparativa e analítica com a proposta teórica de Bachelard (1997), tendo em vista que a relação de Fló com a água é de natureza purificadora, libertadora, no sentido de o personagem, em seu estado de espírito, encontrar quietude e renovação. Não é a liberdade da sociedade que, com os loucos fora dela, vai sentir-se limpa, mas a purificação de si mesmo, enquanto indivíduo que se vê fora das amarras ideológicas. Conforme coloca o crítico:

Pela purificação, participamos de uma força fecunda, renovadora, polivalente. A melhor prova desse poder íntimo é que ele pertence a cada gota do líquido. [...] Sob vários aspectos, parece que a lavagem constitui a metáfora, a tradução em linguagem clara, e que a 
aspersão é a operação real, isto é, a operação que proporciona a realidade da operação. $A$ aspersão é pois sonhada como a operação primordial (BACHELARD, 1997, p. 148).

Ora, Fló precisava ser constantemente mergulhado nas águas dos rios para se sentir limpo e vivo, purificado. Como disse seu irmão ao pai: "a água afina o sangue". Dessa forma, vimos muito da pureza e purificação nessa narrativa de Godoy Garcia que, aliás, também pode ser lida à luz do que Chevalier (2009, p. 15) identifica ser o significado da água: "fonte de vida, meio de purificação, centro de regenerescência". Ainda para o mesmo autor: “Mergulhar nas águas, para delas sair sem se dissolver totalmente, salvo por uma morte simbólica, é retornar às origens, carregar-se, de novo, num imenso reservatório de energia e nele beber uma força nova [...]" (CHEVALIER, 2009, p. 15). Sendo assim, não podemos ler esse conto e deixar de relacioná-lo com os três estudiosos mencionados, uma vez que a questão da água como elemento purificador perpassa por todos e Fló, acima de tudo, é um personagem que só consegue ficar no mundo, porque tem contato com a água enquanto esse elemento vivo, fluido e puro.

Ademais, não apenas a água, mas também o riso que ele sempre carrega no rosto, deixando inquietos os membros da família, é um fator determinante para a vivência de Fló, pois ele tem apenas uma fala no conto, no restante do tempo, ele apenas ri e, quando temos conhecimento de seus pensamentos e desejos é por intermédio da voz do narrador onisciente. Fló é um personagem que se vê silenciado durante toda a narrativa, quase na última página, há uma fala dele: “_ Inda vou rir, vou esperar meu pai chegar". Nesse momento, como prova de que o riso era, também, 
fio condutor de sua existência, ele não ri porque não tem motivos, está triste, sente a falta dos familiares que ficaram para trás (afinal, apesar de sua singularidade e de os outros pensarem que não, Fló sempre sabe de tudo que ocorre a sua volta); agora, é apenas ele e Cinira, todos os outros morreram ou ficaram pelo caminho da "peregrinação". Todavia, ele tem a esperança do retorno do pai para, daí, viver/rir de novo.

Diante desse contexto, voltamos em Foucault (2003), ao ponderar sobre a impossibilidade de o louco ter voz; no silenciamento que gira em torno de sua existência e, claro, da eterna tentativa de exclusão, não só dos loucos, mas de qualquer sujeito considerado das bordas. Contudo, esse sujeito "calado", quando pode, fala por si e pelos outros, além de tudo, fala verdades e percebe o que ninguém mais vê. É um sujeito que anuncia o que está por vir, mas, como sua voz é silenciada, os outros não Ihe dão ouvidos e querem falar por ele. Assim pronuncia Foucault (2001, p. 11): "[...] em contrapartida, que se the atribua, por oposição a todas as outras, estranhos poderes, o de dizer uma verdade escondida, o de pronunciar o futuro, o de enxergar com toda ingenuidade aquilo que a sabedoria dos outros não pode perceber". Fló, então, assemelha-se ao que encontramos em outras personagens da literatura, essa arte cuja linguagem se "avizinha" à loucura, pois endossa e não silencia; ajuda e não atrapalha; comunga e não segrega.

Outra discussão que podemos fazer ao analisar o conto em tela gira em torno da perspectiva teórica de Deleuze (2011), tendo em vista que o crítico tem um pensamento filosófico sobre a literatura de forma que, para ele, a linguagem do texto vai além do limiar, ela possibilita criação de conceitos a serem problematizados, como 
o devir, o trágico, a linha de fuga. Porém, para nós, interessa sua visão do escritor como um "clínico", que diagnostica as mazelas sociais e faz uma literatura menor, no sentido de ser rara e não pequena, uma literatura que evidencia a diferença, a singularidade do indivíduo excluído. O escritor que faz isso não faz apenas externamente, na descrição dos personagens, mas faz na tessitura de toda narrativa, na linguagem, principalmente, que é peculiar e característica de cada um. José Godoy Garcia é um escritor com essa particularidade, na prosa ou na poesia conseguimos identificar um autor que diagnostica a sociedade via linguagem e, com as leituras, percebemos que a língua literária sai do padrão e se reinventa.

A linguagem peculiar pode ser vista em um poema do mesmo autor do conto, que se faz destacar por estar contextualizado com a narrativa e intitula-se "O menino que não sabia morrer". O poema faz parte do livro Os Morcegos (1987) e foi publicado antes do livro de contos. Assim, podemos notar que ele é uma espécie de prólogo de "Florismundo Periquito". O poema é um resumo do conto, o que nos leva a pensar na singularidade da escrita godoyana. Inclusive, identifica-se aqui uma intratextualidade, porque o autor recupera fragmentos de sua própria obra do passado para enriquecer a do presente, ele faz com que sua própria escrita entre em diálogo contínuo, o que permite, aliás, uma leitura mais fluida e compensadora, levando o leitor a identificar esse traço característico.

\section{0 menino que não sabia morrer}

Era um menino que não sabia morrer.

Os outros, sim, os outros mal nasciam, os outros pela estrada nas noites 


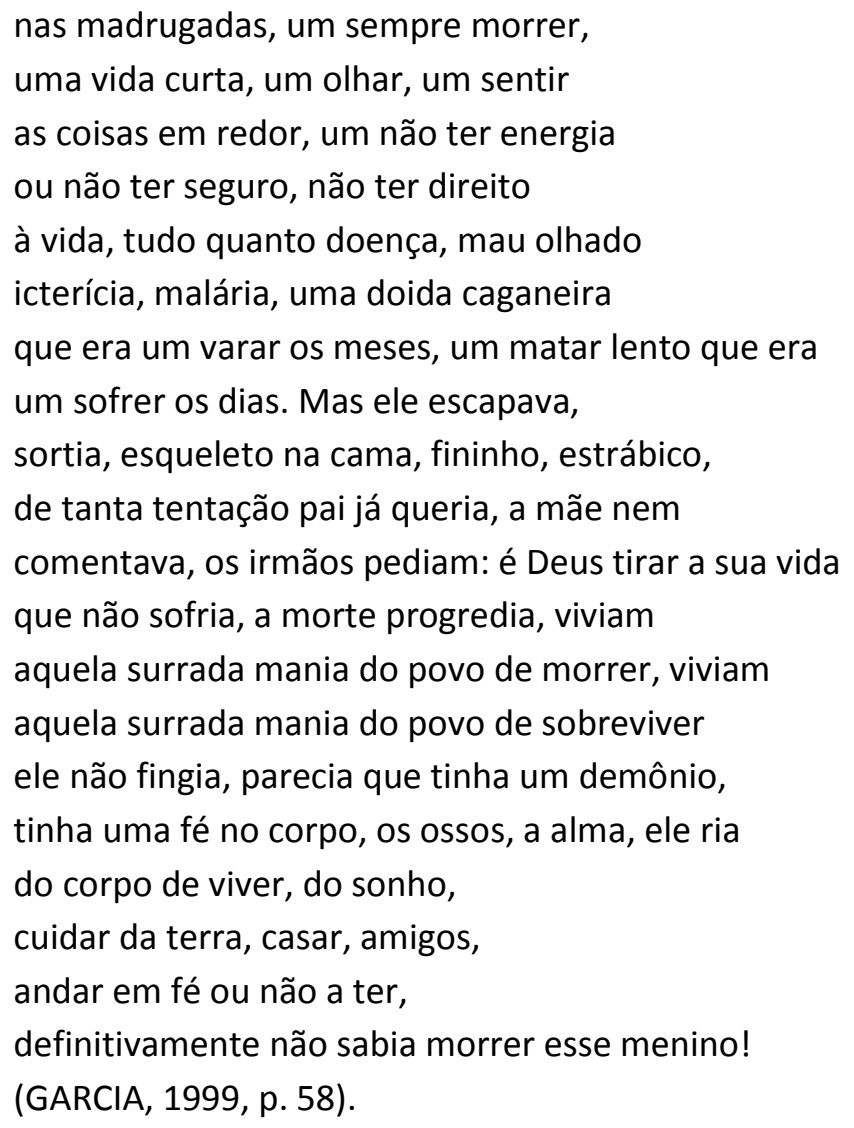

Fló é, portanto, um em meio a tantos personagens singulares, como Macabéa de Clarice Lispector ou Bartleby de Melville, criados por meio de uma linguagem também singular, à luz do modo como seus autores os veem no mundo e lhes confere valor e identidade. Aliás, além de uma identidade, eles têm singularidade, o que os levam a uma desarticulação em relação ao discurso do outro. Há uma quebra de expectativas, já que o personagem não vive como quer a ideologia dominante, pelo contrário, camuflado pela sua "deficiência", ele pode ir contra tudo e todos, mesmo sem fala, como Fló; com a repetição de apenas uma expressão: "I would prefer not to", como Bartleby; ou com a reprodução de palavras da rádio relógio, como Macabéa.

O que torna esses personagens singulares, para Deleuze, é a repetição de suas constantes ações/falas, é isso que os constitui enquanto seres diferentes e autônomos, 
capazes de despertar no leitor algum sentimento: compaixão, dó, raiva, indignação, semelhança. De alguma forma, sua existência não passa em branco, porque a singularidade está no diferente e o diferente é a repetição do mesmo. No caso de Fló, o riso era sua marca distinta, enquanto todos se preocupavam com o que poderia acontecer a eles durante a árdua caminhada, em busca de sobrevivência, Fló apenas ria e sorria, em qualquer circunstância, excetuando o final da narrativa, quando ele se vê só, com uma irmã.

Há excertos na obra que nos comprova a repetição que se torna singularidade: “O Fló, olhando pela boca do saco, esteve rindo, pois as alegrias e tristezas andam sempre juntas" (GARCIA, 1990, p. 76). "Com Fló se deu que não se entregara à aflição, engolia aquela desdita com o riso em sua face. [...] O Fló ria. Por que o Fló se abria naquele riso cheio de maldade naquela hora?" (GARCIA, 1990, p. 77-78). “O Fló não tinha outra saída, senão rir” (GARCIA, 1990, p. 76). “- É um milagre de Cristo esta risada de nosso irmão Fló, Ele vive morrendo, e por qualquer coisinha de nada o Fló sai do saco, põe a cabeça de fora e não tem um dia que ele não abre a boca no riso" (GARCIA, 1990, p. 79).

Fló não via motivos para não sorrir. Era o filho "diferente" e é o personagem que, logicamente, chama mais a atenção na narrativa, o único que "tinha tudo para morrer, mas não sabia", porque só sabia rir. Os demais, sadios, foram ficando pelas passagens. Após a morte de alguns membros da família, Zé Periquito seguiu caminho com os outros. Trabalhou em outras terras e, de tempo em tempo, via partir seus filhos, morrendo de um a um, ou ficando para trás, como Manoel e Perubina. Nas desventuras do caminho, Fló quase morreu, mas deram-lhe um banho nas águas do rio e suas forças foram revigoradas pela natureza. Uma viagem que durou meses, alguns de fartura e outros de 
miséria, chegou ao fim com a morte do pai, restando apenas Fló e sua irmã Cinira, que logo pereceu e ele ficou sozinho no mundo.

Diante desse final aberto, perguntamo-nos: Será para onde vai Fló? Quem o levará para algum lugar? O autor deixa, ao final do conto, apenas essa incógnita e o leitor cheio de dúvidas em relação ao futuro/fim de Fló. Porventura surgiu alguém que o levou para uma casa de repouso, um manicômio, para a "nau dos loucos" ou, um orfanato? Não temos a resposta para tais questionamentos, não sabemos se o mundo foi "higienizado" de Fló. Sabemos apenas que ele ficou sozinho no mundo, como nos diz o narrador, na última linha do conto: "Sim, Fló ficou sozinho no mundo" (GARCIA, 1990, p. 107).

\section{Conclusão}

Esse conto, sendo o mais significativo dentro do livro, aborda um tema bastante peculiar e delicado, que contextualiza um paradoxo. Enquanto existe no garoto uma aparente deficiência física e mental, são as outras personagens que não sabem se comportar nesse mundo indefinido e cheio de preocupações. A luta pela vida de todos os personagens desse conto pode ter sido vã, porém, o espírito de luta que se acende constantemente em Fló, foi o que Ihe garantiu sua sobrevivência.

"Florismundo Periquito", em relação aos demais contos, se sobressai por mesclar em sua tessitura todos os elementos abordados na temática geral da poética godoyana. Nele encontramos a relação do homem com a natureza e o social, o campo e a cidade. É uma narrativa que, segundo Salomão Sousa (2009), citado por Maria Elizete de Azevedo Fayad (2009): "reafirma a humanidade, salva a dignidade do ser humano". 
Enquanto todas as outras pessoas, aparentemente sadias, estavam preocupadas com a saúde do menino doente, ele assistia à morte de todos. Não se preocupava com nada, apenas sonhava, pensava no futuro e gostava de rir. Esse era o seu remédio, o riso, tanto no poema (que pode ser lido como um resumo do conto) quanto no texto em prosa. Os elementos encontrados no conto e no poema facultam, ainda, uma gama de possibilidades de análises e leituras comentadas. Entre eles, os que mais se destacam são: a presença do riso, fonte de vida do garoto; os sonhos e pensamentos, que o faziam viajar; além da pureza da terra e da água encontradas no conto.

Enfim, a obra em prosa de José Godoy Garcia está bem próxima da poética, pois o grande tema da escrita godoyana é relacionar o Ser humano às diversas vertentes, como a social e a política. Há, principalmente na prosa, uma guerra declarada entre as classes sociais, na maioria das vezes representada pela dicotomia governo e povo. Suas técnicas de narrativa e linguagem simples ao relatar os fatos históricos conferem à obra um caráter verossímil. Há uma linearidade que conduz o leitor a entrar na narrativa e se sentir parte da história, tal é a forma com que as palavras são colocadas no texto e a maneira como a leitura flui. As personagens são apresentadas com diálogos, ações, pensamentos, conflitos regionais e culturais, conforme vimos nesta breve leitura que nos permite depreender, em sua totalidade, a essência humanística que se instala nos contos.

Ainda é possível, certamente, analisar o conto sob outras perspectivas, da história e da memória, talvez, da migração e da identidade, quiçá, mas, por hora, escolhemos nos debruçar sob essa vertente mais psicológica e simbólica dos peculiares traços desse personagem tão curioso e rico em detalhes.

\section{Referências}


BACHELARD, G. Pureza e purificação. A moral da água. In: A água e os sonhos.

Tradução Antônio de Pádua Danesi. São Paulo: Martins Fontes, 1997.

CHEVALIER, J. Dicionário de símbolos: mitos, sonhos, costumes, gestos, formas, figuras, cores, números. 24. ed. Rio de Janeiro: José Olympio, 2009.

CORTÁZAR, J. Alguns aspectos do conto. In: Valize de cronópio. 2. ed. São Paulo:

Perspectiva, 1993.

DELEUZE, G. Crítica e clínica. Tradução Peter Pál Pebart. São Paulo: Ed. 34, 1997.

FAYAD, Maria Elizete de Azevedo. Poesia e realismo em Rio do Sono de José Godoy Garcia. 2009. 90f. Dissertação (Mestrado em Letras) - Programa de Pós-Graduação em Literatura, Pontifícia Universidade Católica de Goiás, Goiânia. 2009.

FOUCAULT, Michel. Stultifera navis. In: . História da loucura. São Paulo:

Perspectiva, 2003.

Bartleby, ou a fórmula. In: Crítica e clínica. 2. ed. Tradução Peter Pál Pelbart. São Paulo: Editora 34, 2011, p. 91-117.

GARCIA, José Godoy. Florismundo Periquito. Brasília: Thesaurus, 1990.

GARCIA, José Godoy. Poesia. Brasília: Thesaurus, 1999.

HOHLFELDT, Antonio Carlos. Conto brasileiro contemporâneo. 2. ed. rev. e ampl. Porto Alegre: Mercado Aberto. 1988.

Recebido em 31 de janeiro de 2019.

Aceite em 18 de fevereiro de 2019. 